\title{
Do Brincar do Bebê ao Brincar da Criança: Um Estudo sobre o Processo de Subjetivação da Criança Autista
}

\author{
Camila Saboia ${ }^{1}$ \\ Universidade de São Paulo \\ Christelle Gosmes \\ L'Hôpital Necker Enfant Malades \\ Cristelle Viodé \\ Université de Bourgogne \\ Marluce Gille \\ L'Hôpital Necker Enfant Malades \\ Lisa Ouss \\ Bernard Golse \\ Université de Paris Ve Paris VII
}

\begin{abstract}
RESUMO - O brincar primitivo do bebê poderia nos revelar traços precoces de uma provável organização autística em curso na criança pequena? Em que medida o investimento do bebê face aos objetos do mundo externo e do ambiente poderia ser associado a suas primeiras experiências com o objeto materno? Tais questões são levantadas neste artigo, cujo principal objetivo é abordar o processo de subjetivação da criança autista a partir da correlação entre o brincar primitivo do bebê e o brincar simbólico da criança. Por meio de um estudo longitudinal de bebês com risco de autismo, constatou-se que, desde uma idade precoce, é possível detectar particularidades na maneira como eles investem e interagem com os objetos do ambiente.
\end{abstract}

Palavras-chave: brincar primitivo, brincar simbólico, autismo, relação mãe-bebê

\section{From Baby's Play to Child's Play: A Study on the Subjectivation Process of Autistic Children}

\begin{abstract}
Could the primitive play of the baby reveal early traces of a probable autistic organization underway with the young child? To what extent the investment of the baby with regard to the objects of the external world and the environment could be associated with his first experiences with the maternal object? Such questions are addressed in this article, which main objective is to address the subjectivation process of autistic children, on basis of the relation between the early play of the baby and the symbolic play of the young child. Through a longitudinal study of infants showing risk of autism, it has been found that it is possible to detect at an early age peculiarities in the way they invest and interact with the objects of their environment.
\end{abstract}

Keywords: primitive play, symbolic play, autism, mother-infant relationship

O brincar precoce ou primitivo do bebê poderia nos sinalizar uma possível organização autística em curso? De que maneira podemos associar a qualidade de interação do bebê com os objetos concretos e reais do ambiente com a qualidade de suas primeiras experiências com o objeto materno? Um estudo longitudinal do comportamento de 23 bebês portadores da Síndrome de West (um tipo de epilepsia precoce que pode contribuir para a manifestação de sintomas autísticos) levou-nos a constatar que há uma diferença significativa quanto à qualidade da interação do bebê com os objetos reais e concretos do ambiente - entre os bebês West que apresentam traços autísticos, os bebês West que apresentam um atraso do desenvolvimento, mas sem aparente manifestação da patologia do autismo e bebês saudáveis ("normais"). Tais observações nos permitiram sugerir que

1 Endereço para correspondência: Av. Rouxinol 84, Conj. 86, Indianápolis, São Paulo, SP, Brasil. CEP: 04.516-000. E-mail: camilasaboia@hotmail.com a maneira pela qual o bebê interage, manipula e se lança na exploração dos objetos do ambiente, apresentados por um outro familiar, no contexto de uma proposição de um jogo compartilhado, poderia indicar traços precoces da patologia do autismo na criança.

Ao nos valermos da noção da importância da expressão do brincar precoce do bebê como um indicador do processo de maturação afetiva da criança, somos, por conseguinte, convidados a mencionar a importância do papel do bebê no processo de acesso ao campo da subjetivação da criança noção esta que traz com ela toda a problemática da relação sujeito-objeto, segundo uma lógica na qual predomina a ideia do interpsíquico sobre o intrapsíquico, o que implicaria afirmar que o processo de subjetivação da criança não está associado ao desenvolvimento de estados, organizados segundo a lógica da existência de estruturas bem-definidas e descritíveis, mas ao processo de diferenciação regido pelas trocas interativas mãe-bebê. 
Nesse sentido, dizemos que a satisfação pulsional, o prazer e a construção da realidade psíquica do bebê se constituiriam graças ao encontro com um outro, tal como preconizou Laplanche (1984) ao introduzir o conceito de sedução originária, no qual enfatiza a função da mãe sedutora como condição fundamental para o "despertar" da sexualidade infantil - contrapondo-se ao conceito metapsicológico freudiano que toma a sexualidade infantil como ana-objetal ou endógena, uma vez que para Freud $(1905 / 1987)$ a satisfação pulsional do bebê encontraria sua origem no seu próprio corpo e epiderme.

Se Laplanche (1984) considera que os elementos constitutivos da vida psíquica do bebê constroem-se, fundamentalmente, pelas mensagens sexuais transmitidas inconscientemente pela mãe, os quais, por sua vez, marcariam o caráter do investimento materno responsável pelo processo de subjetivação do bebê, como explicar o comportamento de certos bebês que, desde as primeiras interações com o mundo, mostram-se completamente aversivos e indiferentes aos investimentos maternos? Será que os bebês também seriam providos de conteúdos sexuais precoces responsáveis pelo desencadeamento de certos fantasmas maternos? Pesquisas no campo da detecção precoce do autismo (Laznik, 2006) apontam que o fechamento autístico do bebê influenciaria na qualidade do investimento materno, algo que contribuiria para uma eventual ruptura no laço mãe-bebê, na medida em que a mãe passaria a investir cada vez menos neste bebê que se vê impossibilitado de convocá-la e mesmo de respondê-la narcisicamente na sua função de objeto primordial, contribuindo, assim, para que a dinâmica mãebebê seja marcada por sucessivos desencontros. Supomos, então, que os bebês exerceriam um papel ativo no processo de subjetivação, bem como uma função importante na própria construção de seus sintomas, o que implicaria dizer que o bebê carrega consigo conteúdos e mensagens próprias desveladas no seu encontro com o objeto materno.

$\mathrm{Na}$ esteira desta visão do bebê como coautor no processo de subjetivação, recorremos à noção de objeto não como uma mera "fonte" de pulsão, tal como proposto no modelo da psicanálise clássica, mas sobretudo como um "revelador" daquela. Em outras palavras, consideramos que a relação entre objeto e pulsão não seria mais atravessada por uma lógica de "causalidade", e sim de "relação", na qual prevalece a noção de uma ligação intrínseca com o objeto, tal como preconiza René Roussillon (1999), ao sugerir o termo rapport à l'objet ao termo relation d'objet, visto que o objeto teria, por si mesmo, uma função simbolizante. Isto é, para o autor, o processo de simbolização da criança só se efetuaria na medida em que o objeto a ser simbolizado fosse, simultaneamente, um objeto para simbolizar; desta maneira, dizemos que é com o próprio objeto que se elabora o impacto do objeto - a mãe, enquanto função simbolizante, escapa à criança pela sua alteridade, ao mesmo tempo que lhe fornece meios para que ela [a criança] possa recriá-la e reencontrá-la (Página de onde foi retirada a citação literal).

Para melhor contextualizar essa noção de objeto tomada como nosso referencial, faz-se necessário revisitar o conceito de objeto introduzido por Winnicott em 1968, poucos anos antes de sua morte e, portanto, pouco trabalhado por ele. No artigo intitulado "On the Use of an Object" (1968/1989),
Winnicott dá ênfase à construção da relação objetal da criança pela perspectiva do processo de diferenciação entre a relação de objeto e o uso do objeto.

Winnicott (1987/2002) postula que o processo de maturação psicoafetiva da criança estaria diretamente associado à sua capacidade de "fazer uso do objeto" do ambiente, o que significaria considerar que o objeto desempenha um papel de revelador dos primeiros traços da organização psíquica da criança. Para Winnicott, a condição sine que non para que a criança possa fazer uso dos objetos do ambiente (object-usage) de maneira simbólica e criativa é que ela seja apta a estabelecer uma "relação com o objeto primário": a mãe (object-relating). Esta última, por sua vez, perderia paulatinamente sua posição de objeto primordial para dar lugar ao surgimento do objeto transicional, responsável por proporcionar à criança o sentimento de ilusão de uma "continuidade" entre ela e o objeto.

Entretanto, quando se trata da patologia do autismo, observamos exatamente a ausência desse sentimento de continuidade entre a criança e os objetos do mundo externo, visto que ela tende a apresentar, na maioria das vezes, comportamentos particulares com os objetos reais da realidade compartilhada, comportamentos que evidenciam uma sensação de permanecer "colado ao objeto externo". Esta experiência compromete sua capacidade de fazer uso dos objetos do ambiente de maneira espontânea e criativa, e impediria a criança de se lançar na construção do brincar simbólico. Nesse contexto, vale a pena questionar em que medida a patologia do autismo não estaria associada a uma possível falha do processo transicional - do modo de relação de objeto (object-relating) para o de uso do objeto (objectusage) - vivenciado pela criança.

Para abordar esse processo de transição do modo mais primitivo de a criança se relacionar com os objetos a um modo mais elaborado, parece-nos pertinente evocar as noções winnicottianas de playground e playing. Winnicott (1971/1975) define como playground a expressão do brincar precoce do bebê que se estabelece nos tempos primordiais do seu desenvolvimento, regido pelas primeiras trocas interacionais mãe-bebê. O playing, por outro lado, caracterizar-se-ia como a expressão de um brincar mais elaborado e rico de símbolos, manifestado num momento mais avançado do desenvolvimento maturacional da criança. Winnicott acrescenta ainda que o playground trata-se, na realidade, de um esboço ou de uma "protorrepresentação" do Espaço Potencial, em que a mãe interagiria com seu bebê introduzindo-lhe não somente ela mesma como objeto, mas também os próprios objetos reais e concretos do ambiente, correspondendo ao que Winnicott definiu como a função da apresentação do objeto (object-presenting).

Por esse mesmo viés, podemos citar ainda a contribuição da teoria de E. Jones (1916/1969), que enfatiza a importância dos objetos reais e concretos do ambiente no processo de simbolização da criança. A criança, ao interagir com os objetos externos, exterioriza certos aspectos de si mesma num movimento de elaboração de suas primeiras experiências. Esta ideia nos remete também ao conceito de objeu desenvolvido por Fédida (1978), segundo o qual o corpo da criança se situaria como um objeto externo ao mesmo tempo que ganharia um estatuto de lugar de projeções das 
protofantasias da criança. Em outras palavras, pelo brincar, a criança acederia à "área intermediária" ou ao "espaço potencial", tornando-se assim capaz de fazer uso dos objetos do ambiente de uma maneira simbólica.

Compreende-se, desse modo, que a expressão do brincar ganharia um estatuto de componente "revelador" da organização objetal da criança, dada a sua dupla dimensão: a que proporciona ao bebê aceder ao espaço intermediário e a que, no après-coup, permite à criança elaborar e organizar suas primeiras experiências de objeto. Nesse sentido, situamos este estudo sobre o processo de simbolização da criança junto à questão da construção do brincar do bebê ao brincar da criança. Como exposto anteriormente, essas questões nos convidam a trabalhar o processo de transição do jogo interativo do bebê, ou playground, ao jogo intrassubjetivo da criança, playing, componentes que nortearão os aspectos metodológicos desta pesquisa, descritos a seguir.

\section{Método}

Este trabalho inscreve-se em uma pesquisa maior, intitulada projeto Programme International pour le langage de l enfant (PILE), pesquisa desenvolvida no setor de psiquiatria infantil do Hospital Necker Enfants Malades em Paris/ França, cujo objetivo principal é de estudar os elementos corporais e interativos, precursores da linguagem verbal, de diferentes grupos de bebês que apresentam riscos de sofrimento psíquico. Há, por exemplo, um grupo de bebês prematuros, um de bebês hospitalizados, um de bebês com distúrbios alimentares precoces e, ainda, outro de bebês portadores de Síndrome de West. Como nossa pesquisa aborda a questão dos indicadores de risco de autismo, centralizamos nosso estudo no grupo de bebês com Síndrome de West, visto que muitos bebês que apresentam essa síndrome apresentam no decorrer do seu desenvolvimento sinais associados à patologia do autismo.

A pesquisa PILE visa a estudar o acesso do bebê à linguagem verbal segundo cinco vias complementares: interativa, do desenvolvimento, psicodinâmica, do apego e psicopatológica.

Vale a pena ressaltar que a base de dados da pesquisa PILE constitui-se, especificamente, por sequências de filmes de bebês, com idades entre 3 meses e 4 anos, em interação com suas mães. A dupla mãe-criança é filmada numa pequena sala de vídeo, devidamente adaptada com um sistema de multicâmeras capaz de fornecer imagens precisas do movimento do corpo, do olhar, bem como da qualidade das produções vocálicas dos bebês, os quais seriam estudados por meio do protocolo denominado de transat (cadeira infantil que lembra aquela que chamamos de "bebê conforto").

Este protocolo, criado especificamente para as análises do comportamento do bebê de 3 a 9 meses, é composto por três momentos distintos de duração de três minutos cada: nos primeiros três minutos, a mãe interage livremente com a criança (sequência interação livre); no segundo momento, ela lhe apresenta um objeto (sequência girafa Sophie) ${ }^{1}$; nos

1 Um brinquedo em forma de girafa, que emite sons ao ser balançado pelo bebê. Este brinquedo, chamado girafa Sophie, é bastante familiar aos bebês franceses três minutos finais, ela canta para seu filho, estimulando-o com os movimentos de suas mãos, que acompanham o ritmo da canção (sequência canção).

Dos 9 meses aos 4 anos, as análises das sequências de filmes da díade mãe-bebê são feitas seguindo um novo protocolo, chamado de tapis rouge (tapete vermelho). Este se caracteriza por uma situação de observação do jogo da criança, que brinca livremente com diversos brinquedos disposto de forma padronizada sobre um tapete vermelho, na presença de sua mãe, durante um tempo de 20 minutos. Paralelamente, propõe-se uma bateria de testes psicológicos devidamente adaptados para abordar os cinco aspectos fundamentais do desenvolvimento da criança, antes citados - testes como CIB, Brunet-Lézine, WWPSI, Mac-Arthur, Entretien-R, Mallete-Projective, Histoire à Completer, Autismo PREAUT, CARS, ADI, entre outros.

Sem perder de vista o objetivo específico de nossa pesquisa - que privilegia, sobretudo, a questão do processo de simbolização da criança autista pelo viés da análise da construção do brincar -, optamos por centralizar nosso estudo nos aspectos interativos e psicodinâmicos das crianças do grupo West nas idades de 6 a 36 meses. As análises desses dois aspectos podem nos fornecer resultados interessantes, capazes de elucidar a relação entre as primeiras experiências do brincar do bebê (playground) e a qualidade da expressão do brincar intrassubjetivo (playing).

Além disso, como tínhamos em mente a importância de detectar comportamentos precisos dos bebês West, que sinalizavam a instalação de sintomas precoces do autismo, optamos por distinguir o grupo West em duas categorias:

1. Bebês West apresentando risco de autismo, segundo a escala diagnóstica do autismo PREAUT, (Laznik et al., 2006) aplicada aos bebês nas idades de 4, 6 e 9 meses;

2. Bebês West com atraso do desenvolvimento e sem traços autísticos, segundo a escala de Brunet-Lézine (1965), aplicada nas idades de 12, 18, 24 e 36.

Constatamos que, no grupo composto por 23 crianças West, cinco delas apresentavam traços autísticos, segundo a escala preaut, das quais 3 tiveram uma confirmação do diagnóstico aos 2 anos de idade pela escala Childhood Autistic Rating Scale (CARS) e aos 3 anos pela Autism Diagnostic Interview (ADI). Dessa maneira, organizamos a população específica do nosso estudo em um grupo de 5 crianças apresentando risco de autismo, e outro de 4 crianças com atraso do desenvolvimento. A título de comparação, um terceiro grupo foi formado por 4 crianças "normais", que integravam o grupo controle da pesquisa PILE. Analisamos o comportamento desses bebês, especificamente, nas idades de $6,9,15,24,30$ e 36 meses.

Vale a pena acrescentar que a nossa opção pela idade de 6 meses fundamentou-se na premissa de que seria por volta desta idade que os bebês passam a manifestar um interesse mais significativo pelos objetos inanimados, especialmente quando estes são investidos por suas mães ou por um outro familiar (Stern, 1985/2006). Trata-se, na realidade, do início da construção do espaço potencial e do acesso do bebê ao campo da intersubjetividade, momento que coincidiria com o surgimento dos objetos transicionais. Sabe-se, ainda, que o interesse precoce dos bebês pelos objetos externos 
inanimados torna-se determinante para a instauração da atenção compartilhada do bebê (l'attention conjointe), expressão primeira do brincar compartilhado da criança, facilmente observada em torno dos 9 meses. Isto explica o porquê de acrescentarmos ao nosso estudo a análise de filmes gravados com bebês nesta idade.

Assim, para abordar os aspectos interativos, priorizamos no protocolo transat a sequência do filme na qual o bebê interage com o objeto apresentado por sua mãe (sequência girafa Sophie). A análise desta sequência parece configurar o que Winnicott (1941/1968) definiu como a função da apresentação do objeto - teoria postulada a partir da sua prática do jogo da espátula, realizado durante suas consultas terapêuticas. Por meio de suas observações, Winnicott pôde constatar que a maneira pela qual o bebê manipula e interage com os objetos reais e concretos do ambiente revela, por si só, aspectos importantes dos componentes psíquicos do bebê. Estes aspectos estão diretamente associados à qualidade de suas primeiras vivências com o objeto materno. Consideramos, ainda, que as primeiras expressões do brincar interativo do bebê (playground) são, na realidade, um produto da comodalização das primeiras experiências sensóriomotoras da criança, as quais atuam como a base fundadora da pulsão criativa e, portanto, como alicerce fundamental do processo de simbolização.

Nesse sentido, surgiu a necessidade de levantar em nosso trabalho um estudo minucioso da correlação entre a expressão da qualidade do brincar do bebê com a qualidade da dinâmica interativa da díade mãe-bebê. Para isto, recorremos a Coding Interactive Behaviour (CIB; Feldman, 1998), um instrumento que nos permite avaliar a qualidade das trocas interativas de bebês, entre 2 e 36 meses, com os pais. Este instrumento é composto por 43 indicadores , cotados numa escala que varia de 1 a 5 , sendo que 22 dentre eles referem-se à qualidade do investimento dos pais, classificada a partir de 3 dimensões principais: sensibilidade (sensitivity), intrusão (intrusiveness) e imposição de limites (limit setting), ao passo que o comportamento da criança é mensurado por meio de outros 16 indicadores que contemplam comportamentos do tipo : engajamento (involvement), recuo (withdrawal) e complacência (compliance). Já a qualidade das trocas interativas mãe-bebê, é avaliada por meio de 5 indicadores, os quais abordam o grau de reciprocidade (reciprocity) e estados negativos (negative states) da díade.

Além do estudo da qualidade da relação mãe-bebê, nosso estudo deteve-se em analisar de maneira minuciosa a qualidade da interação do bebê com o objeto-brinquedo (sequência girafa Sophie). Este estudo foi realizado com a ajuda do logiciel EUDICO Linguistic Annotator (ELAN), desenvolvido pelo Instituto Max Planck, da Noruega, em 2007, que nos permitiu examinar a sequência dos filmes em segundos e em milésimos de segundos. Este estudo possibilitou agregar ao protocolo de pesquisa PILE um olhar mais clínico e detalhado das trocas do bebê com sua mãe na presença de um objeto terceiro (a girafa).

Com isso, organizamos a análise dos movimentos de interação do bebê com o objeto girafa durante 3 minutos, partindo de quatro categorias específicas:

A - A criança olha o objeto (categoria que traduz a atenção do bebê ao objeto apresentado pelo adulto);
B - A criança agarra o objeto (categoria que traduz o gesto do bebê de alcançar o objeto para manipulá-lo, o que reflete o primeiro estado de aproximação do bebê para com o objeto);

$\mathrm{C}$ - A criança direciona o objeto à boca (categoria que traduz um segundo estágio de exploração do objeto, marcado pela inauguração de uma exploração mais sutil do objeto pela via da oralidade) $)^{2}$;

D - Respostas sincrônicas entre a díade mãe-bebê (neste item, consideramos qualquer tipo de linguagem gestual da criança para com sua mãe, expressa por respostas sincrônicas e transmodais, além de toda situação de protoconversação e de atenção compartilhada (anttention conjointe) do objeto entre a díade mãe-bebê).

No que diz respeito ao estudo dos aspectos do brincar intrassubjetivo da criança-ou, como definimos anteriormente, do playing, segundo a perspectiva winnicottiana-, optamos pelo teste projetivo chamado Mallette Projective de la Première Enfance (MPPE; Roman, 2005), primeiro teste projetivo adaptado à crianças que se situam no período anterior ao desenvolvimento da linguagem. O teste caracteriza-se por uma situação de observação de jogo da criança, que é convidada a brincar, sem a interferência do observador ou da mãe, presentes na sala, com os brinquedos disponíveis num tapete e organizados de maneira padronizada (urso de pelúcia, telefone, boneca, panelinhas, etc.). A MPPE nos permite avaliar a produção simbólica do brincar da criança de maneira objetiva, sem negligenciar os aspectos transferenciais do clínico-observador nem os aspectos subjetivos e projetivos da criança que brinca. Em outras palavras, a MPPE fornece uma dupla leitura do brincar, no que se refere tanto aos seus aspectos quantitativos como aos qualitativos. Dessa maneira, aplicou-se a MPPE às crianças estudadas nas idades aproximadas de 15, 24 e 36 meses idades em que é possível observar traços de expressões de um brincar mais elaborado, que vem confirmar o acesso da criança ao campo do simbólico.

Enfim, como nossa pesquisa visa também a analisar a relação entre a qualidade da produção simbólica do bebê e a qualidade da dinâmica interativa da díade mãe-bebê, torna-se essencial dar continuidade a essas observações. Para isso, correlacionamos os dados da MPPE com os da CIB - esta aplicada nas idades de 15 e 24 meses, a partir das sequências de filmes recolhidas segundo o protocolo tapis rouge, mencionado antes.

\section{Resultados e Discussão}

Os resultados desta pesquisa foram analisados a partir de uma articulação de dados quantitativos, fornecidos por uma minuciosa leitura estatística- realizada pelo estatístico Christophe Lallane (Institut National de la Santé et de la Recherche Medicale [INSERM] - U 699, França)-,

2 Em referência ao trabalho de Meltzer (1980), que postula a hipótese de que a exploração do objeto pelo caráter oral corresponde ao primeiro meio instrumental pelo qual a criança pode aceder a uma exploração mais rica e detalhada do próprio objeto. Da mesma maneira, Bullinger (2007) defende a ideia de que seria no espaço que circunscreve a boca do bebê que se despertariam as sensibilidades mais profundas associadas a suas experiências táteis. 
com dados qualitativos, baseados numa leitura clínica de orientação psicanalítica. Nesse sentido, nossa pesquisa se inscreve num âmbito que se pretende interdisciplinar, cujo objetivo é buscar justamente a complementaridade entre a criança observada da situação empírica, construída a partir de protocolos preestabelecidos, e a criança da situação da prática clínica analítica.

Os resultados analisados apontam para a direção da nossa hipótese central - a de que haveria, desde a idade de 6 meses, uma diferença significativa, em relação à qualidade de interação da criança com os objetos do ambiente, entre bebês que apresentam risco de autismo, bebês com atrasos de desenvolvimento, sem sinais autísticos e bebês saudáveis. Essa diferença revelaria traços de riscos de autismo à medida que os investimentos sensoriais e pulsionais da criança em relação aos objetos externos do ambiente parecem se organizar, de maneira distinta entre os bebês West, tal como nos mostra a leitura dos resultados das escalas CIB, ELAN e MPPE.

Pelas análises da CIB, constatamos que os bebês West com potencial autístico apresentavam, desde os 6 meses de idade, um comportamento que denuncia uma forte tendência de fechamento e de evitamento das situações que requerem momentos de interação com suas mães, tal como nos revela a presença da categoria withdrawal (recuo) na escala da CIB (índice que varia entre 3 e 5 para os bebês com risco de autismo, enquanto que, para as crianças dos outros dois grupos, sua incidência é nula). No entanto, curiosamente, observou-se que a qualidade de investimento materno do grupo de bebês que apresentavam risco de autismo era comparável à das mães do grupo West com atraso psicomotor e, até mesmo, do grupo controle. Apenas em torno da idade de 9 meses houve uma queda significativa de respostas sincrônicas entre a díade mãe-bebê. Isto se efetivaria devido ao comportamento das mães dos bebês futuros autistas passarem a investir menos na construção de sua relação com eles, como nos indica a queda na categoria sensitivity da escala CIB - que cai consideravelmente de nível 4,5 para 3,5 -, manifestada, por exemplo, na maneira como a mãe dialoga e se endereça a seu bebê, com ausência de picos prosódicos e de mamanhês.

Constata-se que este comportamento da mãe, nesse grupo de bebês com sinais de autismo, intensifica-se ainda mais quando a criança tem por volta de 15 meses, momento no qual parece mostrar-se mais indiferente aos estímulos do ambiente. Este quadro de fechamento de tais crianças torna-se mais perceptível aos 24 meses, quando suas mães se mostram mais intrusivas se comparadas com as dos outros dois grupos. Observa-se, por exemplo, que elas tendem a convocar a criança introduzindo o brinquedo girafa muito próximo ao seu rosto, numa atitude que mais parece um apelo desesperado para tirar a criança de seu estado de "enclausuramento". Esta observação nos leva a deduzir que a qualidade das respostas do bebê influencia diretamente na intensidade do investimento materno, tal como já preconizava Winnicott (1987) ao afirmar que a mãe faz o bebê da mesma maneira que o bebê faz a mãe. Isso nos leva a supor que o bebê teria um papel ativo na formação de seus próprios sintomas.
As análises microscópicas do brincar dos bebês estudados pelo ELAN indicaram que os bebês West com risco de autismo mostram-se menos interessados em explorar o objeto girafa apresentado por sua mãe. Notamos, ainda, que o desinteresse desses bebês em direcionar-se ao objeto, agarrá-lo, manipulá-lo, enfim, em responder ao convite de um brincar compartilhado com sua mãe, não seria decorrente de um provável comprometimento no desenvolvimento psicomotor - quadro comum entre as crianças com síndrome de West -, visto que, ao compará-los com os bebês West com atraso do desenvolvimento, observamos que os últimos se mostram bem mais ativos e interessados em se engajar na brincadeira com o outro; apesar de suas limitações físicas, é nítida a sua curiosidade e seu prazer em compartilhar com o adulto o objeto achado e criado - em referência à dinâmica winnicottiana trouvée/crée.

Além disso, identificamos uma ausência significativa de exploração oral do objeto girafa por parte dos bebês com sinais de autismo na idade de 6 meses (Tabela 1). Esta ausência de investimento libidinal da zona erógena bucal sinaliza uma falha precoce no que se refere à organização das primeiras experiências sensoriais com o objeto, bem como um comprometimento quanto ao investimento pulsional do objeto. Isso parece acentuar-se ainda mais quando observamos que, aos 9 meses, esses bebês exploram o objeto pela boca por meio de gestos pobres e efêmeros, com uma duração média de 0,8 segundos (Tabela 2 ), ao passo que, nos bebês do grupo controle, essa duração poderia se estender até 3,5 segundos, de acordo com os resultados analisados pelo ELAN.

Os resultados de nosso estudo revelaram que os bebês com risco de autismo direcionavam seu olhar ao objeto com uma atenção comparável à dos bebês saudáveis (Tabela 1), o que vem confirmar a hipótese das últimas pesquisas sobre autismo precoce (Maestro \& Muratori, 2002), que enfatizam que os bebês diagnosticados com riscos de autismos não são completamente indiferentes à presença do adulto familiar nem à presença de objetos inanimados quando estes são "investidos" ou "animados". Nesse sentido, a atenção, enquanto função primária, não estaria comprometida; isso só ocorreria no que concerne ao seu caráter de função social, o que provavelmente explica a razão pela qual esses bebês veem, mas não olham, já que o olhar demanda, de fato, uma maior sensibilidade à interação com o outro, bem como à percepção dos objetos externos do ambiente. Esta hipótese

Tabela 1. Frequência média das categorias analisadas por grupo de crianças

\begin{tabular}{ccccccc}
\hline Grupo & Idade & A & B & C & D & Total \\
\hline \multirow{2}{*}{ Autista } & $6 \mathrm{~m}$ & 7.5 & 0.0 & 0.0 & 0.0 & 1.9 \\
& $9 \mathrm{~m}$ & 4.3 & 1,3 & 0.8 & 2,0 & 2.1 \\
Atraso do & $6 \mathrm{~m}$ & 5.0 & 2,5 & 1.0 & 9,0 & 4.4 \\
desenvolvimento & $9 \mathrm{~m}$ & 7.7 & 2,0 & 0.0 & 8.0 & 4.4 \\
Controle & $6 \mathrm{~m}$ & 8.0 & 7.0 & 1.8 & 7.0 & 5.9 \\
& & 5.8 & 8.8 & 1.8 & 8.8 & 6.1 \\
\hline
\end{tabular}

Notas. A: a criança olha o objeto. B: a criança agarra o objeto. C: a criança direciona o objeto à boca. $\mathrm{D}$ : respostas sincrônicas entre a díade mãe-bebê. 
Tabela 2. Duração média de cada categoria

\begin{tabular}{cccccc}
\hline Grupo & Idade & A & B & C & D \\
\hline Autista & $6 \mathrm{~m}$ & $1.9(1.2-4.5)$ & $0.0(0.0-0.0)$ & $0.0(0.0-0.0)$ & $0.0(0.0-0.0)$ \\
& $9 \mathrm{~m}$ & $3.0(2.5-4.0)$ & $1.4(0.3-2.5)$ & $0.8(0.5-1.1)$ & $0.8(0.6-1.2)$ \\
Atraso do desenvolvimento & $6 \mathrm{~m}$ & $5.8(2.3-39.3)$ & $2.8(1.9-14.4)$ & $0.3(0.3-0.5)$ & $2.5(1.8-4.7)$ \\
& $9 \mathrm{~m}$ & $5.8(3.7-15.1)$ & $1.0(1.5-19.1)$ & $0.0(0.6-0.0)$ & $1.7(0.9-5.1)$ \\
Controle & $6 \mathrm{~m}$ & $6.8(2.6-14.5)$ & $1,9(1,9-13,8)$ & $0.8(0.3-3.6)$ & $3.4(1.8-5.3)$ \\
& & $6.7(2.3-12.0)$ & $2.2(1,5-15,7)$ & $0.5(0.6-3.5)$ & $3.6(2.2-9.2)$ \\
\hline
\end{tabular}

Notas. A: a criança olha o objeto. B: a criança agarra o objeto. C: a criança direciona o objeto à boca. D: respostas sincrônicas entre a díade mãe-bebê.

talvez explique a dificuldade observada no bebê autista de sustentar seu olhar e sua atenção ao objeto girafa quando ele é introduzido e apresentado por sua mãe.

Constatamos, por exemplo, que esses bebês West autistas, na idade de 6 meses, sustentam seu olhar ao objeto numa duração média 5 segundos menor se comparada à do grupo de bebês saudáveis, e 4 segundos menor em relação à do grupo de bebês West com atraso do desenvolvimento (Tabela 2). Esta diferença torna-se ainda mais considerável aos 9 meses de idade, quando observamos que os bebês West autistas são capazes de manter sua atenção ao objeto girafa, "investido" por sua mãe, por no máximo 4 segundos, ao passo que, para os bebês normais, essa duração pode ser de até 12 segundos.

Os resultados do ELAN referentes às respostas sincrônicas entre a díade mãe-bebê, que correspondem às trocas interativas do bebê com sua mãe na presença do objeto terceiro (girafa), apresentam respostas de incidência zero, sugerindo um comprometimento da sintonia afetiva (accordage affectif; Stern, 1985/2006) e, por conseguinte, da atenção compartilhada (attention conjointe) do bebê.

No que diz respeito à análise dos resultados da MPPE referentes ao brincar intrassubjetivo da criança, pôde-se observar que as crianças autistas na idade de 15 meses mostraram-se resistentes a se engajar na exploração dos objetos disponíveis no tapete - isto é, no que configurava o teste MPPE. Entre as idades de 24 e 30 meses, essas mesmas crianças passavam a interessar-se pelos brinquedos da MPPE, embora de maneira pobre e estereotipada - as explorações eram feitas sem intencionalidade, ou seja, sem que houvesse de fato a presença de um investimento pulsional em relação a esses objetos. A criança, por exemplo, pegava o patinho de borracha e o esfregava com movimentos repetitivos sobre o tapete do jogo; em seguida, de modo aleatório, pegava outro brinquedo para manipulá-lo de forma mecânica. Observou-se, assim, que as interações das crianças com os objetos eram marcadas, predominantemente, por explorações de caráter sensorial, ao contrário do que se dava com as crianças do grupo controle e com as crianças que apresentam atraso do desenvolvimento, tal como apontou o gráfico da leitura dos resultados estatísticos da MPPE (Figura 1) . $^{3}$.

Por volta dos 30 meses, verificamos um maior investimento das crianças em relação aos objetos, visto que agora elas os exploravam oralmente. Essas explorações de caráter oral sugerem uma apropriação da região erógena

3 Observa-se aqui uma diferença significativa entre as crianças A5 e A4 e as outras crianças do mesmo grupo: ambas não tiveram o diagnóstico de autismo confirmado aos 3 anos.

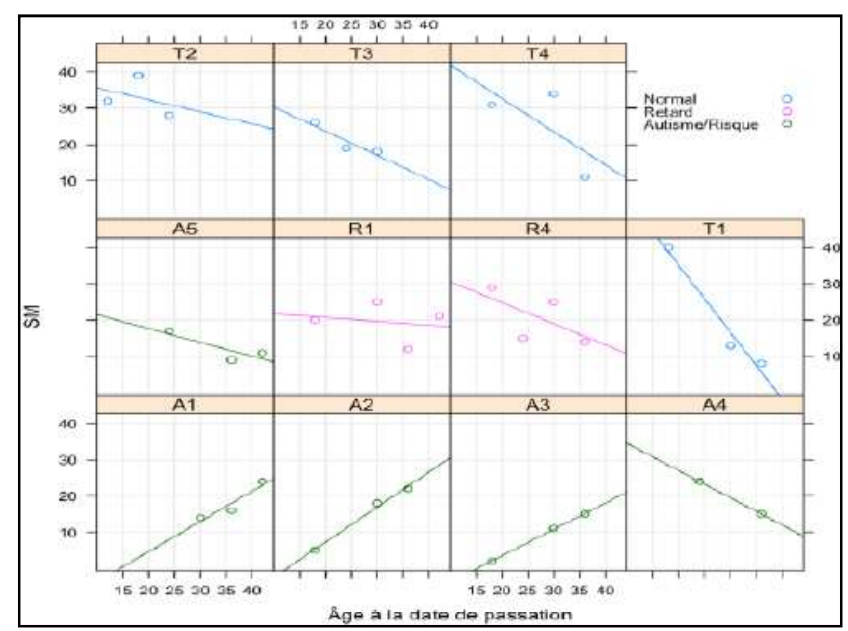

Figura 1. Explorações sensoriais dos objetos do jogo da MPPE (SM) vs. idade em que a MPPE foi aplicada à criança. Azul $=$ crianças saudáveis. Rosa $=$ crianças com atraso do desenvolvimento. Verde $=$ crianças com autismo.

bucal no processo de integração da imagem corporal da criança. Supõe-se que, à medida que tais crianças conquistam esse novo registro corporal, sua relação com os objetos do ambiente passa a ganhar uma nova condição: se antes elas tinham uma tendência de evitar e ignorar os objetos do jogo, o que mostra seu funcionamento segundo um registro ana-objetal, agora elas passam para um estado objetal, em que há intencionalidade de interagir e explorar os objetos do jogo, ainda que de forma estereotipada ou por meio de objetos autísticos.

Em seguida, aos 36 meses, quando as crianças autistas apresentaram uma melhor organização de sua imagem corporal bem como de sua organização espaçotemporal, observamos nelas uma maior sensibilidade e interesse em explorar os objetos do ambiente, sendo isso concretizado por meio das explorações sonoras - elas, por exemplo, pegavam os objetos e os batiam uns contra os outros, num movimento ritmado, na busca de produzir sons. É interessante destacar aqui que esses comportamentos parecem ilustrar a ideia preconizada pela psicanalista italiana Suzanne Maiello (1991), segundo a qual a construção da relação objetal da criança se edificaria graças às experiências regidas pelo ritmo e pela musicalidade, entre o bebê e o mundo externo.

Podemos, porém, facilmente detectar que essas explorações sonoras rapidamente ganham um caráter mecânico e estereotipado, fazendo jus à hipótese de que a única forma que essas crianças encontram para estabelecer 
uma relação entre o eu e os objetos externos do ambiente seria, provavelmente, por intermédio dos objetos autistas.

\section{Considerações Finais}

Por meio do estudo longitudinal dos três grupos de bebês analisados nesta pesquisa, pôde-se observar, ao final do trabalho, uma importante correlação entre a qualidade do brincar primitivo ou precoce desses bebês (playground) e a expressão do brincar intrassubjetivo dessas mesmas crianças (playing) apresentada na idade de 24 meses. Observou-se, assim, que os bebês que tendiam a ser mais resistentes em se engajar no convite de um brincar compartilhado com o adulto familiar (playground) - momento no qual a mãe se relaciona com seu bebê a partir da função descrita por Winnicott como função da apresentação do objeto (object-presenting) - demonstraram, ulteriormente, um comprometimento na qualidade do investimento dos objetos externos do ambiente, representado por exemplo, pela incapacidade dessas crianças em explorar os objetos do jogo da MPPE de maneira rica e simbólica.

Constatou-se, ainda, que os primeiros indícios da maneira como o bebê está vivenciando e organizando suas primeiras relações objetais - ou seja, do modo como ele está fazendo uso dos objetos do ambiente - aparentam ser um importante sinalizador do desenvolvimento psíquico do bebê, uma vez que se pôde perceber que os bebês com risco de autismo apresentavam, desde a idade precoce de 6 meses, uma forma particular de explorar e brincar com o objeto girafa, forma esta marcada, em especial, por explorações sem ritmo e sem intencionalidade, que parecem posteriormente vir a comprometer a atenção compartilhada do bebê, tal como pudemos observar aos 9 meses de idade. Estas evidências sugerem, ainda, possíveis entraves no processo constitutivo da criança, o que parece ser confirmado no après-coup ao constatarmos a ausência do brincar simbólico destas crianças aos 24 meses.

Dessa maneira, pudemos inferir que o desinteresse dos bebês West autistas em pegar, explorar e manipular o objeto girafa apresentado por sua mãe não se justificaria somente por problemas associados a certas limitações motoras, uma vez que verificamos que os bebês West com atraso do desenvolvimento mostraram-se curiosos e mesmo capazes de explorar o brinquedo girafa, assim como se mostraram capazes de brincar com os brinquedos do teste MPPE de forma criativa e simbólica - mesmo que de modo limitado, quando comparados às crianças do grupo controle.

Assim, concluímos que os nossos resultados parecem elucidar nossa hipótese inicial, na qual a patologia autística da criança poderia ser associada a uma possível falha do processo de transição entre o modo mais primitivo de se relacionar com o objeto (object-relating) e o modo mais elaborado, momento em que a criança passa a fazer uso dos objetos de maneira rica e simbólica (object-usage). Em outras palavras, pudemos concluir que o estudo da transição entre o brincar precoce do bebê (playground) e o brincar simbólico da criança (playing) poderá talvez nos servir como um importante norteador para pensar o processo de subjetivação da criança, bem como suas possíveis falhas e deslizes - como no caso das crianças ditas autistas.

Enfim, concluímos que o brincar parece ganhar um caráter primordial no processo constitutivo do sujeito na medida em que ele é tomado pela sua dupla dimensão - ou seja, é por meio dele que o bebê acede ao campo transicional -, ao mesmo tempo que nos revela, no après coup, aspectos importantes da maneira como o bebê pôde vivenciar e elaborar suas primeiras relações objetais.

\section{Referências}

Bullinger, A. (2007). Le développement sensori-moteur de l'enfant et ses avatars. Un parcours de recherche. Paris: Eres.

Brunet O., \& Lezine I. (1965) Échelle de developement psychomoteur de la première enfance. Manuel d'instructions. Paris: Editions Scientifique et Psycho-tecnique.

Fédida, P. (1978). L'“Objeu”. Objet, jeu et enfance. L'espace psychotérapeutique. In P. Fédida, L'absence (pp. 137-281). Paris: Gallimard

Feldman, R. (1998). Coding interactive behaviour manual (Unpublished manual). Israel: Bar-Illan University.

Freud, S. (1987). Trois essais sur la théorie de la sexualité. Paris: Gallimard. (Trabalho original publicado em 1905)

Jones, E. (1969). La théorie du symbolisme. In E. Jones, Théorie et pratique de la psychanalyse (A. Stronck, Trad., pp. 83-133). Paris: Payot. (Trabalho original publicado em 1916)

Laplanche, J. (1984). La pulsion et son objet source: Son destin dans le transfert. In D. Anzieu, R. Dorey, J. Laplanche \& D. Widlöcher (Eds.), La pulsion pour quoi faire? (pp. 9-24). Paris: Association Psychanalytique de France.

Laznik, M.-Ch. (2006). Pré-aut: Une recherche et une clinique $\mathrm{du}$ très précoce. Comment passer de ces bébés qui troublent leurs parents à des petits qui auraient plaisir à s'amuser avec eux. Contraste: Enfance et handicap. Revue de l'ANECAMSP, 25, 53-80.

Maestro, S., \& Muratori, F. (2002). Les films familiaux. Le Carnet Psy, 75, 35-36.

Maiello, S. (1991) L'objet sonore - Hypothèse d'une mémoire auditive prénatale. Journal de la Psychanalyse de l'Enfant, " Le corps », 20, 40-66.

Meltzer, D., Bremner, J., Hoxter, S., Weddel, D., \& Wittenberg, I. (1980). Explorations dans le monde de l'autisme. Paris: Payot.

Roman, P. (1997). La méthode projective comme dispositif à symboliser. In P. Roman (Dir.), Projection et symbolisation chez l'enfant (pp. 37-51). Lyon: PUL.

Roman, P. (2005). La Mallette Projective Première Enfance (MPPE): un outil clinique pour l'évaluation de la personnalité du jeune enfant. Devenir, 17(3), 233-259.

Roussillon, R. (1999). Agonie, clivage et symbolisation. Paris: PUF. Stern, D. N. (2006). Le monde interpersonnel du nourrisson. Paris: PUF. (Trabalho original publicado em 1985) 
Winnicott, D. W. (1968). L'observation des jeunes enfants dans une situation établie. In D. W. Winnicott, De la pédiatrie à la psychanalyse (J. Kalmanovitch, Trad., pp. 37-56). Paris: Payot. (Trabalho original publicado em 1941)

Winnicott, D. W. (1987). A mãe dedicada comum. In Os bebês e suas mães. São Paulo: Martins Fontes, 2002.(pp. 1-11)
Winnicott, D. W. (1989). On the use of an object. In D. W. Winnicott, Psycho-analytic Explorations (pp. 217-246). London: Karnac Books. (Trabalho original publicado em 1968)

Winnicott, D. W. (1975). Jeu et réalité. Paris: Gallimard. (Trabalho original publicado em 1971)

Recebido em 25.06.2015

Primeira decisão editorial em 18.07.2016

Versão final em 13.04.2016

Aceito em 20.06.2017 